\title{
Prevalência do aleitamento materno e práticas de alimentação complementar em crianças com até 24 meses de idade na região do Alto Jequitinhonha, Minas Gerais
}

\author{
Breastfeeding prevalence and complementary feeding practices \\ in children up to 24 months old in Alto Jequitinhonha region, \\ Minas Gerais, Brazil
}

Francisco José Ferreira da SILVEIRA ${ }^{1}$

Joel Alves LAMOUNIER²

\section{R E S U M O}

\section{Objetivo}

Determinar a freqüência e duração do aleitamento materno e identificar as práticas relacionadas à alimentação complementar em municípios do Alto Jequitinhonha.

\section{Métodos}

Estudo transversal, com 450 crianças desde o nascimento até os 24 meses de idade, nos municípios de Carbonita, São Gonçalo do Rio Preto e Datas. A coleta de dados foi feita através da aplicação de questionários em entrevistas com as mães. As análises foram feitas utilizando-se os programas Epi Info versão $6.04 \mathrm{~b}$ e SPSS versão 8.0 .

\section{Resultados}

Medianas de 10,85 meses para amamentação, 3,85 meses para amamentação completa e 1,51 meses para amamentação exclusiva. Foram observadas em relação à área de residência, as medianas de amamentação foram 9,70 para área urbana e 16,00 para área rural. Com menos de 1 mês de vida, 33,6\% das crianças já recebiam chás e $12,4 \%$ recebiam água. O consumo de carne foi de $40,5 \%$ e fruta de $44,1 \%$, na faixa etária de 6 e 12 meses de idade, nas últimas 24 horas. Houve associação estatisticamente significativa entre residir na área rural e menor consumo de sucos, frutas, verduras/legumes e carne nas crianças maiores de 1 ano.

\footnotetext{
1 Departamento de Medicina Preventiva e Social, Faculdade de Ciências Médicas de Minas Gerais. Alameda Ezequiel Dias, 275 , Centro, 30130-110, Belo Horizonte, MG, Brasil. Correspondência para/Correspondence to: F.J.F. SILVEIRA. E-mail: saujr@uol.com.br

2 Departamento de Pediatria, Faculdade de Medicina, Universidade Federal de Minas Gerais. Av. Alfredo Balena, 190, Santa Efigênia, 30130-100, Belo Horizonte, MG, Brasil.
} 


\section{Conclusão}

A duração da amamentação nos três municípios foi maior do que em outros estudos recentes no país, porém a amamentação exclusiva continua sendo pouco praticada. Alimentos complementares de baixo valor nutritivo são iniciados precocemente, e alguns alimentos são fornecidos com pouca freqüência após 6 meses de idade.

Termos de Indexação: prevalência, aleitamento materno, suplementação alimentar.

\section{A B S T R A C T}

\section{Objective}

To determine the frequency and duration of breastfeeding and to identify the practices related to complementary feeding in cities of Alto Jequitinhonha.

\section{Methods}

A cross-sectional study was carried-out in the cities of Carbonita, Datas e São Gonçalo do Rio Preto. Data were collected of a sample of 450 children from birth to 24 months of age, using a questionnaire in interviews with the mothers. For the analisys, Epi Info version $6.04 \mathrm{~b}$ and SPSS version 8.0 were used.

\section{Results}

The duration medians were 10.85 months for breastfeeding, 3.85 months for complete breastfeeding and 1.51 months for exclusive breastfeeding. The medians of breastfeeding were 9.70 months for urban area and 16.00 in rural area. Before 1 month of life, 33.6\% of the mothers had introduced tea and $12.4 \%$ had introduced water to their infants. Meat was used by $40.5 \%$ and fruit by $44.1 \%$ of the children aged from 6 to 12 months. Living in rural area was associated with ingesting less juice for children aged from 6 to 12 months and with less juice, fruit, vegetables and meat for children above 12 months of age.

\section{Conclusion}

The duration of breastfeeding was longer than demonstrated in other recent studies, but exclusive breastfeeding is yet little practiced. Complementary foods with low nutritious value are introduced precociously, and some nutritions foods are not given frequently after 6 months of age.

Index terms: prevalence, breast Feeding, suplementary feeding.

\section{N T R O D U Ç Ã O}

Os hábitos alimentares de crianças em regiões pobres são pouco conhecidos, apesar da importância de melhor compreender as reais carências e necessidades existentes nestas populações. A amamentação exclusiva é considerada a prática alimentar mais adequada para a criança até 6 meses de idade'; só então devem ser introduzidos outros alimentos, denominados complementares, além da manutenção do aleitamento materno.
Apesar das recomendações sobre o aleitamento materno exclusivo até 6 meses de idade, esta prática não é freqüente, conforme mostram as pesquisas realizadas em diversas regiões do país; mesmo o aleitamento materno, independentemente do uso de outros alimentos, apresenta uma duração inferior à desejada, apesar do aumento dos índices a partir da década de $70^{2-6}$.

O retorno às práticas de amamentação ocorreu inicialmente nas elites urbanas de países 
desenvolvidos, após a ampla divulgação dos seus benefícios, o que explica o fato de, nesses países, a amamentação ser mais praticada entre os grupos de melhor nível socioeconômico ${ }^{5,7}$. No Brasil, esta tendência é observada em vários estudos realizados, principalmente em grandes áreas urbanas e em regiões mais desenvolvidas ${ }^{3,7-9}$. Além disso observa-se que, de modo geral, em países subdesenvolvidos, principalmente nas regiões mais pobres, as mães de nível socioeconômico mais baixo e as que residem em áreas rurais amamentam mais ${ }^{10,11}$.

Como a prática adequada do aleitamento materno tem uma repercussão favorável para a saúde infantil, conforme demonstram vários trabalhos publicados sobre o assunto, passou a fazer parte importante do planejamento do setor de saúde de instituições governamentais ${ }^{12-16}$. Considera-se a prática correta da alimentação complementar, fundamental no combate à desnutrição infantil, pois o período crítico do desenvolvimento do déficit nutricional se dá entre 6 e 24 meses de idade. Para as crianças amamentadas, a Organização Mundial de Saúde (OMS) recomenda 3 refeições diárias de alimentos complementares, a partir de 6 meses e com menos de 12 meses de idade, e 5 refeições a partir de 12 meses de idade ${ }^{17}$. Os 3 principais tipos de alimentos recomendados são: os de alta densidade energética, os de alto conteúdo protéico e os ricos em vitaminas e sais minerais.

Considerando-se a importância da alimentação adequada para o crescimento normal, necessita-se de estudos com análises da situação da amamentação e de outros hábitos de alimentação infantil, para obter-se informações que contribuam para o desenvolvimento de estratégias de intervenção alimentar.

O presente estudo foi realizado em municípios do Alto Jequitinhonha, região mais pobre e menos desenvolvida do estado de Minas Gerais. Os resultados poderão auxiliar no direcionamento de ações de combate ao desmame precoce e à prevenção de desnutrição e outras doenças carenciais. Os objetivos foram determinar a freqüência e duração do aleitamento materno naqueles municípios e identificar as práticas relacionadas à alimentação complementar em crianças com até 24 meses de idade.

\section{CASUÍSTICA E MÉTODOS}

O estudo foi conduzido nos municípios de Carbonita, São Gonçalo do Rio Preto e Datas, na região do Alto Jequitinhonha, em Minas Gerais. As três cidades pertencem ao Consórcio Intermunicipal de Saúde do Alto Jequitinhonha (CISAJE) e são subordinadas à Diretoria Regional de Saúde de Diamantina, e se localizam respectivamente a 30, 50 e 120 quilômetros desta cidade. Estes municípios foram selecionados para estudo por terem cobertura total do Programa de Saúde da Família (PSF) e por serem campo de estágio curricular do Internato Rural da Faculdade de Ciências Médicas de Minas Gerais, fatores que ajudaram a viabilizar a pesquisa. A população destes municípios é de aproximadamente $11 \mathrm{mil}$ habitantes em Carbonita, 3 mil habitantes em São Gonçalo do Rio Preto e 5100 habitantes em Datas. O poder aquisitivo da população é extremamente baixo nos 3 municípios, sendo as atividades econômicas principais a exploração madeireira e a carvoaria em Carbonita, e a agropecuária em São Gonçalo do Rio Preto e Datas.

O estudo foi transversal e observacional. Para efeito de amostragem consideraram-se todas as crianças até 24 meses de idade nos 3 municípios. De acordo com dados coletados junto às administrações municipais, a estimativa fornecida era de aproximadamente 550 crianças, sendo 280 em Carbonita, 160 em Datas e 110 em São Gonçalo do Rio Preto. Em Datas, durante o trabalho de campo, o número de crianças encontradas foi menor. Acredita-se que isto tenha ocorrido devido a uma superestimação do número de crianças, e também pela migração em determinados períodos do ano nesta região, quando muitas famílias se deslocam, principalmente para o interior de São Paulo e outras regiões de Minas Gerais, para trabalho na 
agricultura. Portanto, o número total de crianças para análise foi de 450 .

Dados sobre aleitamento materno, hábitos alimentares e aspectos socioeconômicos foram colhidos em julho de 2000, em entrevistas com mães ou responsáveis pelas crianças, por alunos de Medicina da Universidade Federal de Minas Gerais (UFMG) e da Faculdade de Ciências Médicas de Minas Gerais (FCMMG). Na área urbana, a coleta de dados foi feita no Centro de Saúde; nas áreas rurais, em locais previamente escolhidos, de acordo com as condições de cada localidade (postos de saúde, escolas, centros comunitários). O recrutamento das mães e crianças foi feito nos domicílios, com o auxílio dos agentes comunitários de saúde. As crianças foram pesadas em balanças pediátricas (com divisões de 10 gramas) e medidas com réguas antropométricas, em decúbito dorsal. Os alunos foram treinados em relação à utilização dos questionários e todo o trabalho de treinamento e coleta de dados foi realizado mediante supervisão do investigador.

Foi utilizado um questionário dividido em etapas, planejado para obter as informações necessárias à realização do estudo. Era parte integrante um recordatório de 24 horas, com a finalidade de coletar dados sobre as práticas atuais de alimentação. Os questionários foram testados em um estudo piloto com 10 crianças em cada município.

Os dados foram analisados em microcomputador, utilizando-se o programa Epi Info versão 6.04b. Foi também utilizado o programa SPSS versão 8.0 para a análise de sobrevivência e cálculo da duração do aleitamento materno. Construíram-se tábuas de vida para aleitamento materno exclusivo, aleitamento materno completo e aleitamento materno. Este método permite incluir na análise as crianças que ainda recebem o leite materno, em cada uma destas modalidades. Foram utilizados os indicadores de aleitamento materno propostos pelo grupo de trabalho da Organização Mundial da Saúde ${ }^{18}$ :

- Aleitamento Materno Exclusivo (AME): o leite materno é o único alimento da criança, a exceção de medicamentos.
- Aleitamento Materno Predominante (AMP): o leite materno é a principal fonte de alimento da criança, porém esta recebe também outros líquidos (água, chás, sucos, etc.). Neste caso, não se incluem crianças que recebem outro leite e/ou alimentos semi-sólidos.

- Aleitamento Materno Completo (AMC): amamentação exclusiva e amamentação predominante.

- Aleitamento Materno Complementado (AMCD): a criança recebe leite materno e alimentos semi-sólidos e/ou sólidos.

- Aleitamento Materno (AM): recebe leite materno, independente do uso de qualquer outro alimento.

A pesquisa foi aprovada pela Câmara do Departamento de Pediatria da Faculdade de Medicina e pelo Comitê de Ética em Pesquisa da Universidade Federal de Minas Gerais, e autorizada pelas mães das crianças através da assinatura de um termo de consentimento.

\section{RES ULTA DOS}

O número total de crianças estudadas foi de 450, desde o nascimento até os 24 meses completos, sendo que 234 (52,0\%) eram do sexo masculino e 216 (48,0\%) do feminino. Em relação à faixa etária, 21,8\% tinham menos de 6 meses, $25,1 \%$ de 6 a 11 meses, $24,4 \%$ de 12 a 17 meses e $28,7 \%$ de 18 a 24 meses. Por município, foram estudadas 254 crianças em Carbonita, 99 em São Gonçalo do Rio Preto e 97 em Datas. Em relação ao total de crianças, 65,9\% residiam na área urbana e $34,1 \%$ na área rural.

A população, de baixo poder aquisitivo, apresentou 234 crianças (85,3\%) pertencentes a famílias com renda per capita abaixo de meio salário mínimo e 216 (61,3\%) pertencentes a famílias com renda per capita inferior a $\mathrm{R} \$ 50,00$. Porém, esta situação não é homogênea quando se comparam as zonas urbana e rural; na zona urbana, $49,0 \%$ das crianças pertenciam a famílias com renda per capita menor de $\mathrm{R} \$ 50,00$, enquanto 
que na zona rural o percentual referente a esta renda menor foi de $85,0 \%$.

Em relação aos hábitos alimentares, 97,9\% das crianças foram amamentadas; no momento do estudo, 216 (48,0\%) do total ainda recebiam o leite materno, porém apenas $21(4,7 \%)$ encontravam-se em aleitamento materno exclusivo (AME).

As curvas de sobrevivência referente a aleitamento materno, aleitamento materno completo e aleitamento materno exclusivo estão demonstradas na Figura 1. As taxas de aleitamento materno foram de $97,08 \%$ antes de 1 mês, 77,81\% com 3 meses, 62,14\% com 6 meses, $41,73 \%$ com 12 meses.

Em relação ao aleitamento materno exclusivo as porcentagens foram de $60,00 \% \mathrm{com}$ menos de 1 mês, 13,65\% com 3 meses, 0,84\% com 6 meses. As medianas foram de 1,51 meses para aleitamento materno exclusivo, 3,85 meses para aleitamento materno completo e de 10,85 para aleitamento materno.
As curvas de duração estimada do aleitamento materno em áreas urbana e rural, evidenciando-se uma tendência de maior tempo de amamentação em crianças da área rural estão demonstradas na Figura 2. As medianas de aleitamento materno foram de 9,70 e 16,00 meses, respectivamente, nas áreas urbana e rural. O teste de Log Rank, para comparação de curvas de sobrevivência, obteve $p=0,01$, portanto uma diferença estatisticamente significativa.

Em relação à introdução de outros alimentos, os chás foram os preferidos nos primeiros meses de vida, sendo que antes do final do primeiro mês, 33,6\% já o recebiam, e antes de 2 meses, 48,4\% já recebiam estes líquidos. Água foi oferecida em $12,4 \%$ dos casos, antes de 1 mês, e em 25,8\%, antes de 2 meses. Os sucos foram dados em menor quantidade; para $2,7 \%$ das crianças com menos de 1 mês de vida, e em 8,2\%, com menos de 2 meses; contudo, com 4 meses, 55,1\% já recebiam este alimento. As sopinhas começaram a ser oferecidas com 1 mês de vida (0,9\% das crianças), com aumento
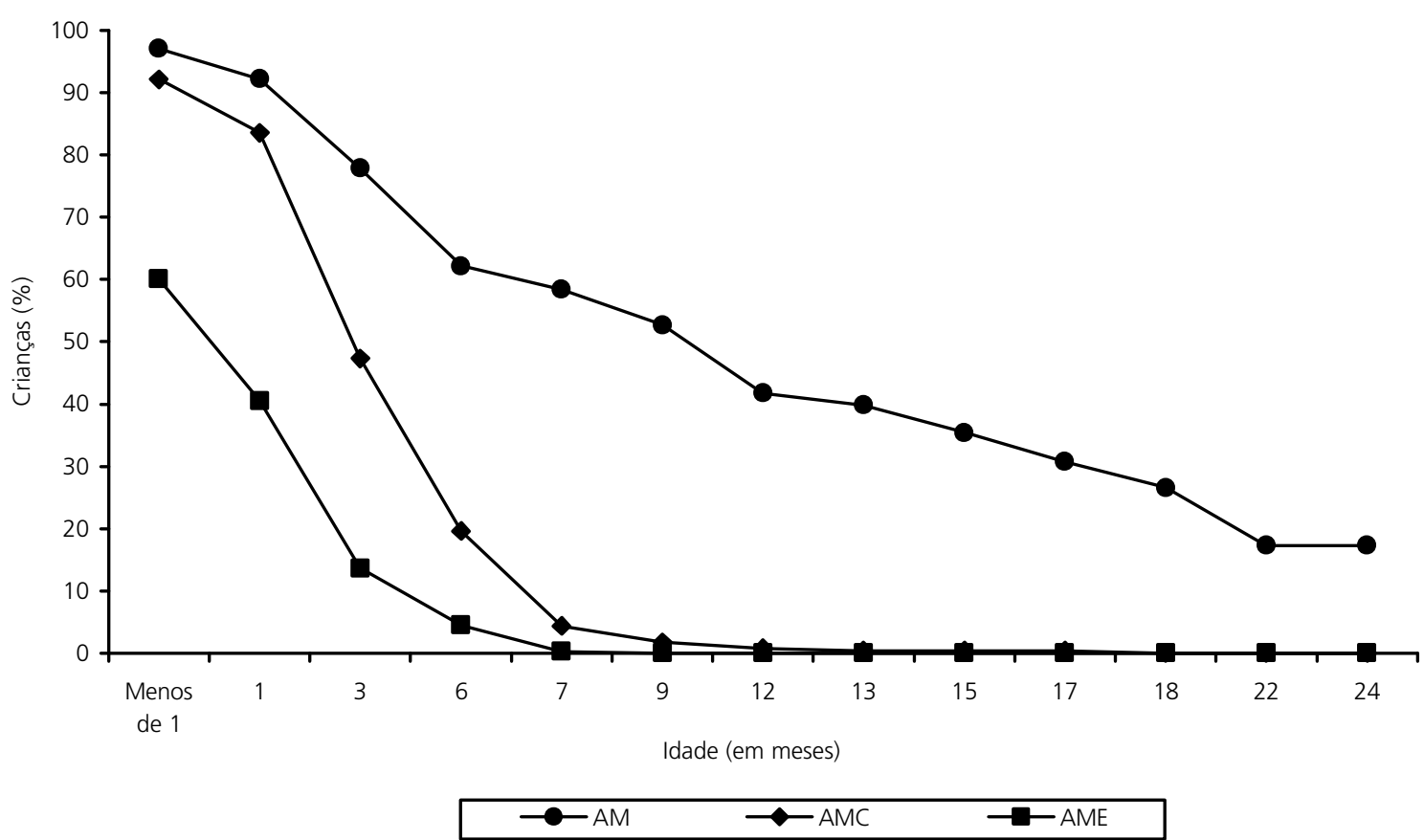

Figura 1. Curvas de sobrevida de aleitamento materno, aleitamento materno completo, aleitamento materno exclusivo. Alto Jequitinhonha, 2000. 
progressivo até os 4 meses (42,4\%). Leite (em pó ou de vaca) já alimentavam $8,0 \%$ das crianças com menos de 1 mês e 18,0\% com 1 mês de vida, oferecidos, preferencialmente, sob a forma de leite em pó; porém, a partir do $2^{\circ}$ mês de vida, o leite de vaca era mais utilizado (Tabela 1).

Na Figura 3 é demonstrada a freqüência de consumo de alguns alimentos nas 24 horas que antecederam a pesquisa pelas crianças de 6 a 12 meses de idade; a Figura 4 mostra a freqüência de consumo de alguns alimentos na faixa etária de 13 a 24 meses.
Os sucos e as frutas, respectivamente, participaram do cardápio de $35,1 \%$ e $44,1 \%$, das crianças de 6 a 12 meses, e de 48,3\% e 49,4\% das crianças com mais de 12 meses. Angu foi consumido por $15,3 \%$ das crianças na faixa etária de 6 a 12 meses e por 23,7\% daquelas com 12 a 24 meses de idade. Arroz com feijão estavam no cardápio de $66,7 \%$ das crianças de 6 a 12 meses e de $87,7 \%$ daquelas com mais de 12 meses. Carne, sem origem especificada, foi consumida por $40,5 \%$ das crianças de 6 a 12 meses e por $66,1 \%$ daquelas com mais de 12 meses.

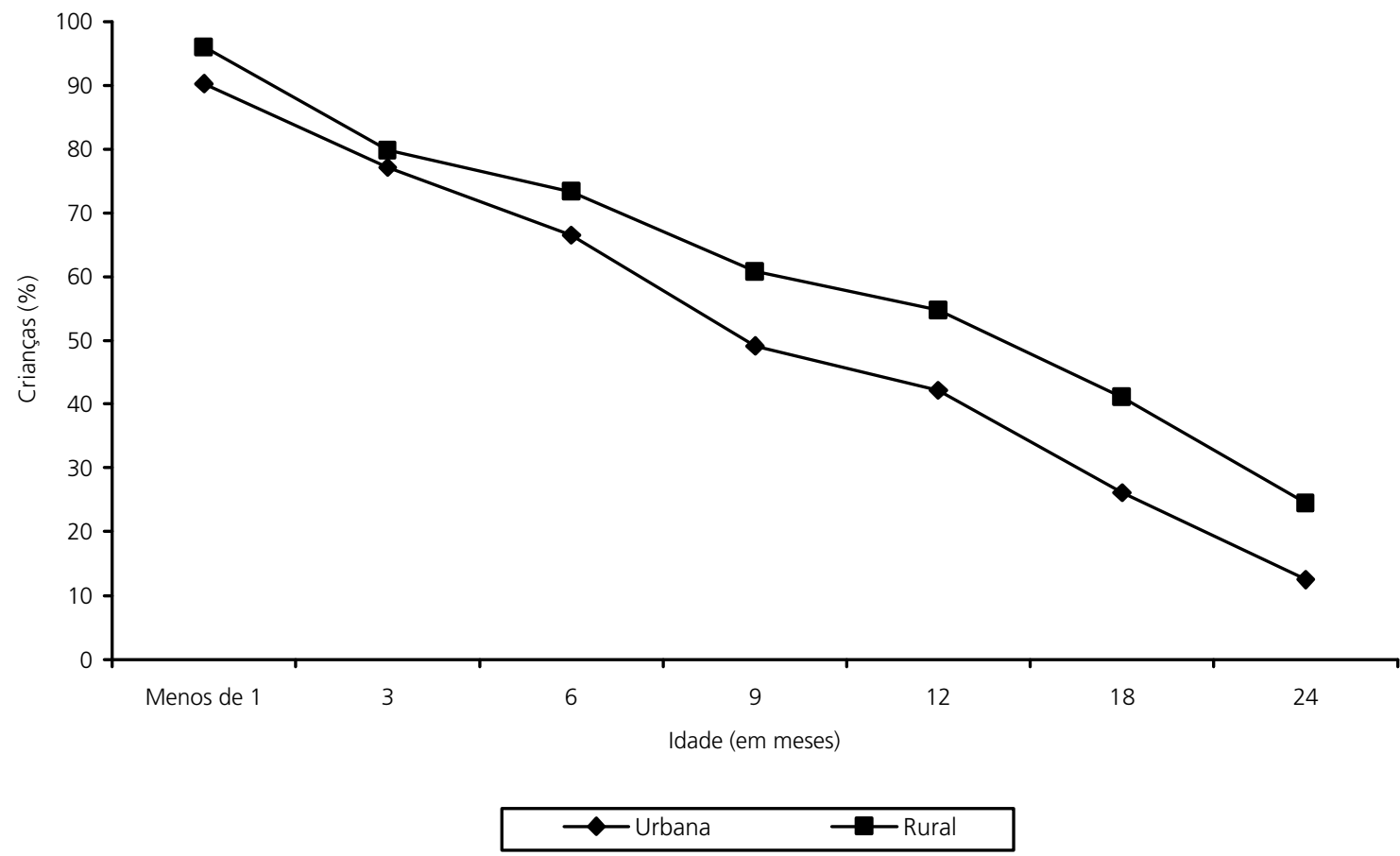

Figura 2. Curvas de sobrevida de aleitamento materno nas áreas urbana e rural. Alto Jequitinhonha, 2000.

Tabela 1. Freqüência de utilização de alimentos complementares pelas crianças, de acordo com a idade (em meses), nos primeiros 4 meses de vida. Alto Jequitinhonha, 2000.

\begin{tabular}{|c|c|c|c|c|c|c|c|c|c|c|}
\hline \multirow{2}{*}{ Alimentos utilizados } & \multicolumn{2}{|c|}{ Menos de 1 mês } & \multicolumn{2}{|c|}{1 mês } & \multicolumn{2}{|c|}{2 meses } & \multicolumn{2}{|c|}{3 meses } & \multicolumn{2}{|c|}{4 meses } \\
\hline & $n$ & $\%$ & $n$ & $\%$ & $n$ & $\%$ & $\mathrm{n}$ & $\%$ & $n$ & $\%$ \\
\hline Chás & 151 & 33,6 & 218 & 48,4 & 268 & 59,6 & 311 & 69,1 & 333 & 74,0 \\
\hline Água & 56 & 12,4 & 116 & 25,8 & 209 & 46,4 & 294 & 65,3 & 342 & 76,0 \\
\hline Sucos & 12 & 2,7 & 37 & 8,2 & 98 & 21,8 & 193 & 42,9 & 231 & 55,1 \\
\hline Sopinha & 0 & 0 & 4 & 0,9 & 20 & 4,4 & 95 & 21,1 & 191 & 42,4 \\
\hline Leite de vaca & 14 & 3,1 & 42 & 9,3 & 74 & 16,4 & 118 & 26,2 & 152 & 33,8 \\
\hline Leite em pó & 22 & 4,9 & 39 & 8,7 & 70 & 15,6 & 100 & 22,2 & 113 & 28,0 \\
\hline
\end{tabular}




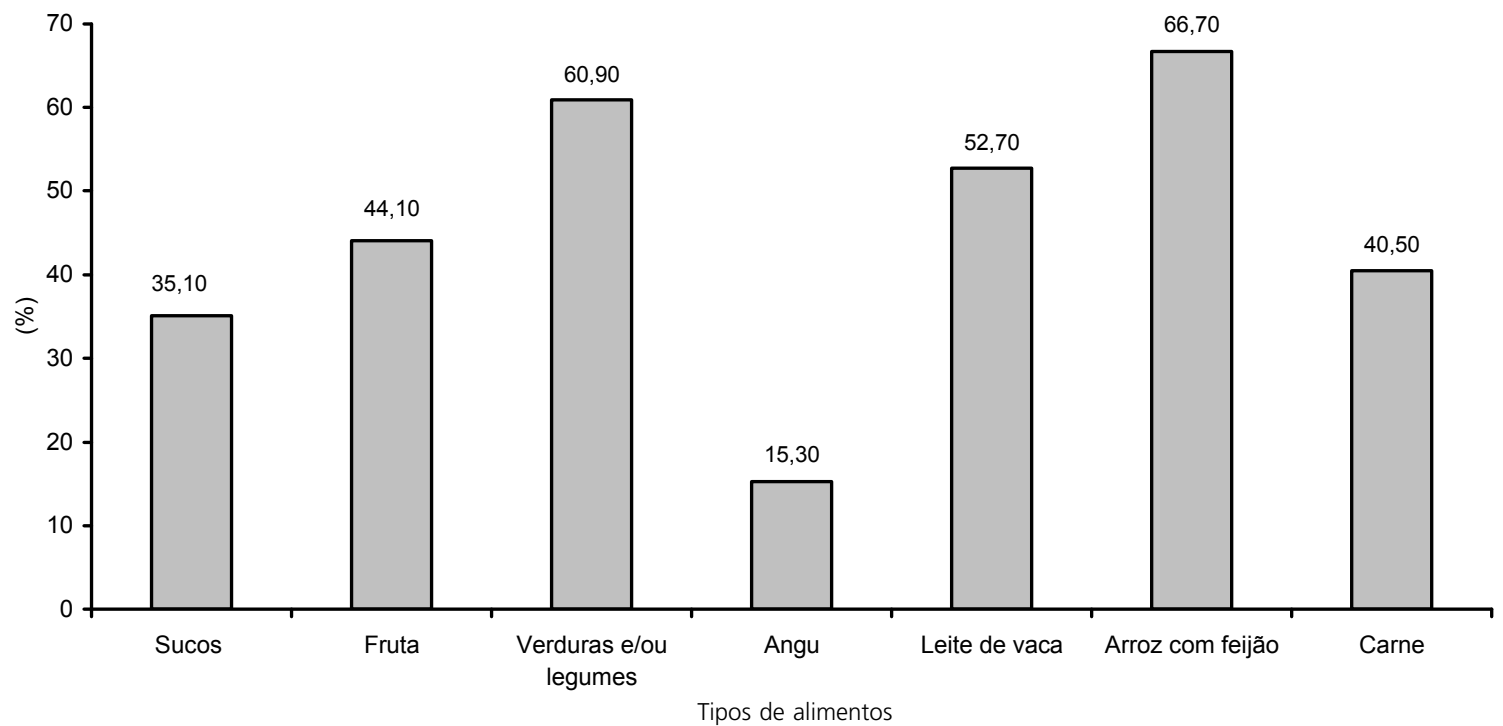

Figura 3. Alimentos recebidos pelas crianças de 6 a 12 meses de idade nas 24 horas que antecederam a pesquisa. Alto Jequitinhonha, 2000 .

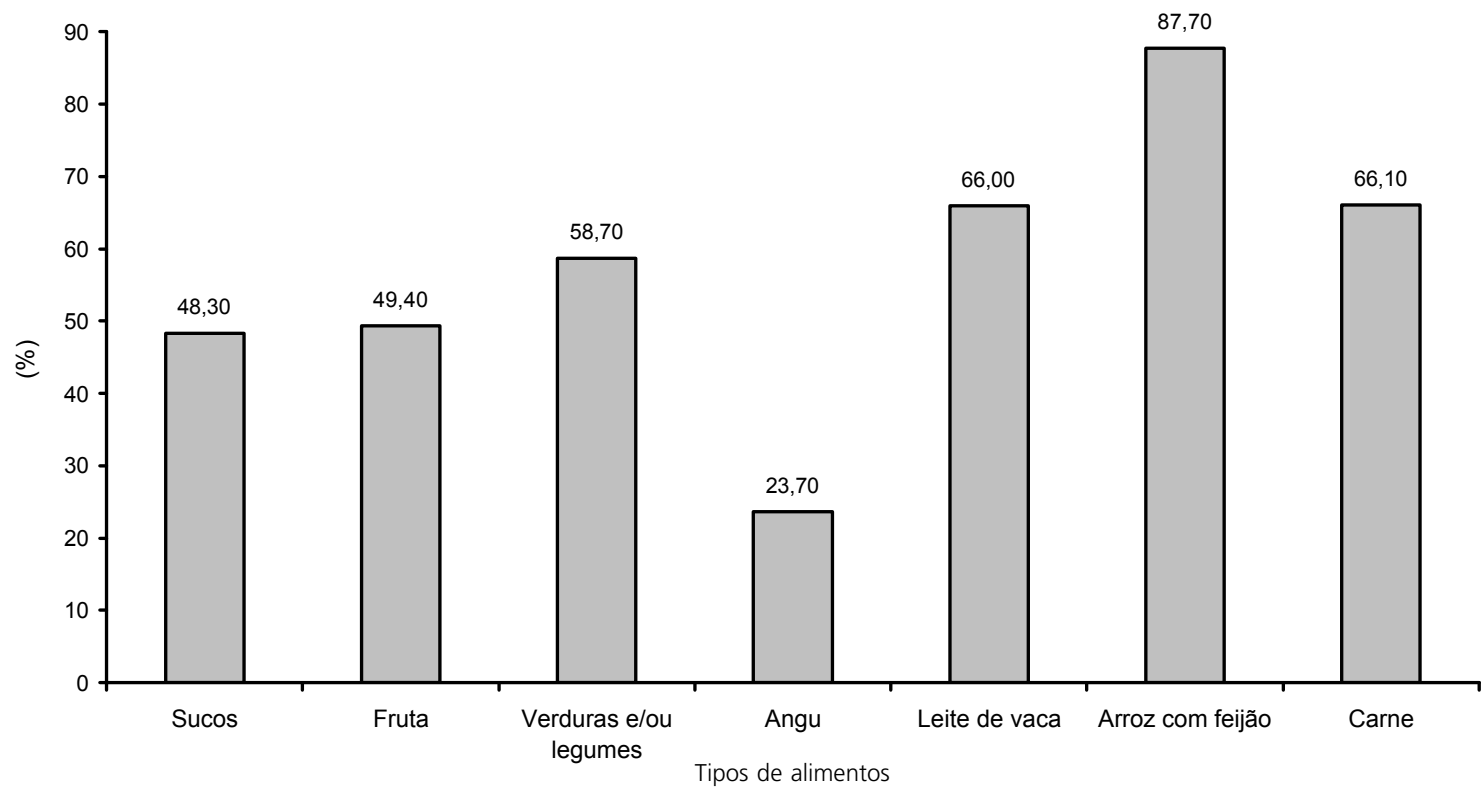

Figura 4. Alimentos recebidos pelas crianças de 13 a 24 meses de idade nas 24 horas que antecederam a pesquisa. Alto Jequitinhonha, 2000.

Tabela 2. Consumo de alimentos, de acordo com a área de residência, em crianças com mais de 12 meses de idade. Alto Jequitinhonha, 2000.

\begin{tabular}{lcccccc}
\hline \multirow{2}{*}{ Tipos de alimentos } & \multicolumn{2}{c}{ Área Urbana } & & \multicolumn{2}{c}{ Área rural } & \multirow{2}{*}{ Teste do qui-quadrado } \\
\cline { 2 - 3 } & \multicolumn{1}{c}{ Sim } & Não & & Sim & Não & \\
\hline Arroz com feijão & 139 & 19 & & 67 & 10 & $p=0,99$ \\
Verduras/legumes & 103 & 54 & & 35 & 42 & $p=0,005$ \\
Carne & 118 & 40 & & 37 & 40 & $p=0,00009$ \\
Sucos & 85 & 13 & & 28 & 49 & $p=0,02$ \\
Frutas & 88 & 69 & & 28 & 49 & $p=0,007$ \\
\hline
\end{tabular}


Analisou-se a relação entre residir em área rural ou urbana e o consumo de alguns alimentos. Em crianças entre 6 e 12 meses de idade, não houve associação estatisticamente significativa entre o consumo de frutas, carne e legumes/verduras e sua área de residência; mas houve uma tendência de maior consumo de sucos na área urbana. Ao se analisar as crianças com mais de 12 meses de idade, verifica-se o consumo de carnes, frutas, sucos e verduras/legumes significativamente maior pelas que residem na área urbana (Tabela 2). Não se observou diferença no consumo de arroz com feijão de acordo com a área de residência, em nenhuma das faixas etárias.

\section{I S C U S S Ã O}

O trabalho foi realizado com uma população de baixo poder aquisitivo, o que se comprova pela proporção elevada de famílias com baixa renda per capita. Alguns estudos demonstraram maiores índices de freqüência e duração do aleitamento materno em populações pobres, principalmente em áreas rurais ${ }^{10}$, o que foi confirmado neste estudo. No Brasil, há uma tendência a diminuir esta diferença, seguindo os padrões que foram observados em países desenvolvidos, porém isto acontece principalmente em regiões de melhor nível de desenvolvimento socioeconômico ${ }^{5}$. Neste estudo, constatou-se ainda uma duração do aleitamento materno significativamente maior do que em outros estudos recentes realizados em Minas Gerais e no Brasil 2,19-21, com exceção da pesquisa realizada no norte do estado de Minas Gerais ${ }^{22}$, que apresentou valores semelhantes (352 dias de mediana para aleitamento materno). Em relação ao aleitamento materno exclusivo, a mediana de 1,51 meses não é satisfatória, estando distante do que recomenda a OMS, ou seja, aleitamento materno exclusivo até 6 meses de idade.

Os hábitos de alimentação infantil nestas populações dependem de padrões culturais, em que as mães introduzem precocemente alimentos complementares, porém, de baixo valor nutritivo, enquanto amamentam por períodos relativamente longos. Os alimentos complementares mais utilizados no início da vida foram os chás $(48,4 \%$ das mães o ministravam a bebês com um mês de vida). Fatores que influenciam esta prática são as crenças populares de que os chás tenham propriedades terapêuticas, como no combate às cólicas $^{23}$. Sucos e principalmente água também foram introduzidos precocemente em numerosos casos, refletindo hábitos culturais e o fato de as mães não serem orientadas para a mudança, continuando a crer do hábito, pois que estes líquidos são necessários para os bebês. Leite em pó e leite de vaca são introduzidos mais tarde, mas num aumento progressivo, demonstrando que, embora a população tenha hábitos positivos em relação ao aleitamento materno, a mamadeira também é bastante utilizada. Inicialmente o leite em pó é mais usado e posteriormente aumenta o uso de leite de vaca. Uma explicação provável é o fato de a população e os profissionais de saúde considerarem os leites industrializados mais adequados para recém-nascidos e lactentes. Posteriormente, as mães de famílias de mais baixo poder aquisitivo, principalmente das áreas rurais, em geral utilizam o leite de vaca in natura, de menor custo.

A introdução precoce de alimentos complementares em lactentes, além de não oferecer vantagens, tem efeitos negativos bem conhecidos, relacionados à morbidade infanti ${ }^{17}$. Os dados que comprovam baixos índices do aleitamento materno exclusivo em todo o país são, portanto, preocupantes, principalmente em regiões mais pobres, onde a mudança de hábitos teria uma repercussão positiva na morbi-mortalidade infantil. Além disso, as famílias nestes bolsões de pobreza, certamente já não têm condições de obter alimentos adequados e, portanto, a introdução desnecessária e precoce de alimentos complementares só aumenta as despesas familiares.

É necessário melhorar os índices de aleitamento materno exclusivo, superando algumas dificuldades, tais como o hábito do 
aleitamento materno de forma não exclusiva, ainda considerado adequado pelas mães. Além disso, é necessário a participação efetiva dos serviços de saúde, principalmente maternidades e serviços de atenção básica. Embora as vantagens do aleitamento materno sejam conhecidas atualmente pela maioria dos profissionais de saúde e por grande parte da população, o aleitamento materno exclusivo ainda não é igualmente aceito pelas mães em geral. São necessárias ações concretas no sentido de promover esta prática, mudando-se o comportamento, num processo participativo dos vários segmentos da sociedade, desenvolvendo na população e nos profissionais de saúde a consciência dos efeitos negativos que tem para a saúde infantil a introdução precoce de outros alimentos. A melhoria destes índices é desejável principalmente em regiões pobres, como a estudada, onde há prevalência considerável de desnutrição infantil.

O resultado positivo observado neste estudo em relação à duração do aleitamento materno, provavelmente se deve, nestas comunidades, à aceitação deste hábito como a alimentação natural de suas crianças, com pouca influência de fatores prejudiciais, como marketing de alimentos infantis pseudo-substitutos do leite materno. Para crianças com 6 ou mais meses de idade, a dificuldade de acesso a outros alimentos, pode também determinar necessidade de amamentar por mais tempo. No entanto, os índices de aleitamento materno, principalmente de forma exclusiva, devem ser melhorados. É importante ressaltar que não há programas destinados especificamente a melhorar os índices de aleitamento materno nos três municípios. Os programas existentes são apenas os de combate à desnutrição através do fornecimento de suplementos alimentares, sem ações específicas de promoção e apoio ao aleitamento materno, os quais podem ter efeitos negativos, em casos de distribuição indiscriminada de leite, ao diminuir os índices de amamentação. O Programa de Saúde da Família (PSF) se destina principalmente à atenção primária, e sua participação seria importante para alcançar-se estes objetivos; porém, é necessário haver um posicionamento efetivo do programa neste sentido, com o treinamento dos recursos humanos envolvidos.

Em relação aos hábitos de alimentação complementar das crianças de 6 a 24 meses de idade, verificou-se que alguns alimentos são pouco consumidos. Apesar da metodologia do estudo não permitir uma análise mais profunda sobre a ingestão dos vários componentes da dieta, alguns componentes, como arroz com feijão e carnes parecem estar sendo pouco consumidos, principalmente por crianças de 6 a 12 meses de idade, o que pode dever-se, em parte, a hábitos culturais. Os pais ainda têm receio de oferecer alimentos semi-sólidos e sólidos a crianças menores, preferindo as sopinhas, geralmente diluídas. Como a participação do leite materno no fornecimento de nutrientes diminui após os 6 meses de idade, o baixo consumo de alimentos com alta densidade protéica e energética pode fazer com que haja carência nutricional em um período crítico do desenvolvimento infantil. Em populações mais carentes, arroz com feijão suprem satisfatoriamente estas necessidades ${ }^{3,5}$. As carnes, principalmente bovina; representam importante fonte de ferro, e as frutas são facilitadoras da absorção deste elemento. Portanto, o baixo consumo destes alimentos pode favorecer o desenvolvimento de anemia ferropriva ${ }^{24}$. Além disso, as carnes são a principal fonte de zinco, cuja deficiência pode afetar o crescimento e desenvolvimento ${ }^{17}$. A partir de 12 meses de idade, há um aumento no consumo de todos os alimentos, com exceção de verduras e legumes, os quais, provavelmente, eram oferecidos às crianças sob a forma de papinhas, quando as crianças tinham menos de 1 ano de idade. Porém, mesmo nesta faixa etária, menos da metade ingeriu alguma fruta nas últimas 24 horas e 66,1\% ingeriu algum tipo de carne, evidenciando a dificuldade de acesso da população a estes alimentos.

O baixo consumo de alimentos nas crianças de 13 a 24 meses de idade, com exceção de arroz com feijão, nas áreas rurais, quando comparada 
à área urbana, provavelmente reflete as condições de vida precárias destas populações que, mesmo residindo em locais potencialmente produtores de alimentos, têm maior dificuldade de acesso a estes. O fato de não haver diferença significativa de consumo alimentar nas crianças de 6 a 12 meses, entre áreas urbana e rural, provavelmente se deve a fatores culturais, sendo que em ambas as populações há ainda receio em relação à introdução de alguns alimentos para crianças menores.

\section{CONCLUSÃO}

A mediana de duração do aleitamento materno de 10,85 meses para os municípios de Datas, Carbonita e São Gonçalo do Rio Preto pode ser considerada satisfatória, principalmente no caso da zona rural, que apresentou mediana de 16,00 meses. No entanto, para o aleitamento materno exclusivo, que é a prática alimentar recomendada para crianças com até 6 meses de idade, os resultados são insatisfatórios. É necessário, portanto, melhorar os hábitos alimentares das crianças na população estudada, pois alimentos complementares de baixo valor nutritivo são introduzidos de forma precoce, com todas as desvantagens decorrentes deste hábito.

Os resultados deste estudo sugerem, que, antes de 1 ano de idade, as práticas alimentares inadequadas podem estar relacionadas a fatores culturais e, nas crianças maiores, a dificuldades de acesso a alguns alimentos pelas famílias mais carentes, principalmente na zona rural. O aumento do poder aquisitivo permitiria o acesso a alguns alimentos, principalmente em crianças maiores de um ano, mas é importante também disseminar-se as informações necessárias, possibilitando à população a mudança para hábitos alimentares adequados. Estas ações poderiam ser priorizadas pelo PSF, principalmente com a utilização dos Agentes Comunitários de Saúde. No entanto, para melhorar o estado nutricional destas crianças, são necessárias mudanças estruturais mais amplas, com alternativas que melhorem as condições de vida, principalmente na zona rural, onde é difícil o acesso a alimentos essenciais. Esforços devem ser feitos para diminuir a taxa de desmame precoce e também para melhorar a qualidade dos alimentos complementares oferecidos à população infantil, já que neste período da vida, as deficiências de nutrientes fundamentais trazem prejuízos, às vezes permanentes, para a saúde física e mental.

\section{REFERÊ NCIAS}

1. Giugliani ERJ. O aleitamento materno na prática clínica. J Pediatr 2000; 76 Supl 3:S238.

2. Pesquisa Nacional sobre Demografia e Saúde. Rio de Janeiro: Benfam; 1997. 180p.

3. Kummer SC, Giuglia ERJ, Susin LO, Folletto JL, Lermen NR, Wu VYJ, et al. Evolução do padrão de aleitamento materno. Rev Saude Publica 2000; 34:143-8.

4. Assis $A M O$, Prado MS, Freitas MCS, Silva RCR, Ramos LB, Machado AD. Prática do aleitamento materno em comunidades rurais do semi-árido baiano. Rev Saude Publica 1994; 28:380-4.

5. Venancio SI, Monteiro CA. A tendência da prática da amamentação no Brasil nas décadas de 70 e 80. Rev Bras Epidemiol 1998; 1:40-9.

6. Lamounier JA. Tendências do aleitamento materno no Brasil. Rev Méd Minas Gerais 1999; 9:59-65.

7. Giugliani ERJ, Issler RMS, Justo EB, Seffrin CF, Hartmann RM, Carvalho NM. Risk factors for early termination of breast feeding in Brazil. Acta Paediatr 1992; 81:484-7.

8. Monteiro CA, Zuniga HPP, Benicio MHD, Rea MF, Tudisco ES, Sigulem DM. The recent revival of breast-feeding in the city of São Paulo, Brazil. Am J Public Health 1987; 77:964-6.

9. Gigante DP, Victora CG, Barros FC. Nutrição maternal e duração da amamentação em uma coorte de nascimento de Pelotas, RS. Rev Saude Publica 2000; 34:259-65.

10. Pérez-escamilla R. Patrones de la lactancia natural en América Latina y el Caribe. Bol of Sanit Panam 1993; 115:185-93. 
11. Grummer-Strawn LM. The effect of changes in population characteristics on breastfeeding trends in fifteen developing countries. Int J Epidemiol 1996; 25:94-102.

12. Dewey KG, Heinig MJ, Nomnsen-Rivers LA. Differences in morbidity between breast-fed and formula-fed infants. J Pediatr 1995; 126:696-702.

13. Victora CG, Vaughan JP, Lombardi C, Fuchs SMC, Gigante LP, Smith PG, et al. Evidence for protection by breast-feeding against infant deaths from infectious diseases in Brazil. Lancet 1987; 319-21.

14. Cesar JA, Victora CG, Barros FC, Santos IS, Flores JA. Impact of breast feeding on admission for pneumonia during postneonatal period in Brazil: Nested case-control study. Br Med J 1999; 318:1316-20.

15. Cunningham AS, Jelliffe DB, Jelliffe EFP. Breast-feeding and health in the 1980s: A global epidemiologic review. J Pediatr 1991; 118: 659-66.

16. Howie PW, Forsyth JS, Ogston SA, Clark A, Florey $C V$. Protective effect of breast feeding against infection. Br Med J 1990; 300:11-6.

17. Giugliani ERJ, Victora CG. Alimentação complementar. J Pediatr 2000; 76 (Supl 3):S253.
18. Organização Mundial de Saúde. Indicadores para evaluar las prácticas de lactancia materna. Genebra: OMS; 1991.

19. Vieira GO, Glisser M, Araújo SPT, Sales NA. Indicadores do aleitamento materno na cidade de Feira de Santana, Bahia. J Pediatr 1998; 74:11-6.

20. Caldeira AP, Goulart EMA. A situação do aleitamento materno em Montes Claros, Minas Gerais: estudo de uma amostra representativa. J Pediatr 2000; 76:65-72.

21. Passos MC, Lamounier JA, Silva CAM, Freitas SN, Baudson MFR. Práticas de amamentação no município de Ouro Preto, MG, Brasil. Rev Saude Publica 2000; 34:617-22.

22. Secretaria de Estado da Saúde de Minas Gerais. Saúde materno infantil em Minas Gerais e norte de Minas. Belo Horizonte; 1997.

23. Giugliani ERJ. Amamentação exclusiva e sua promoção. In: Carvalho MR, Tamez RN. Amamentação: bases científicas para a prática profissional. Rio de Janeiro: Guanabara Koogan; 2002. p.11-24.

24. Barbieri D, Palma D. Gastroenterologia e nutrição. Rio de Janeiro: Atheneu; 2001.

Recebido para publicação em 18 de fevereiro e aceito em 19 de novembro de 2003. 